\title{
A clínica psicológica em uma inspiração fenomenológica - hermenêutica
}

\section{The psychological clinic influenced by phenomenology - hermeneutic}

\author{
Ana Maria Lopez Calvo de Feijoo* \\ Universidade do Estado do Rio de Janeiro - UERJ, Rio de Janeiro, RJ, Brasil
}

\begin{abstract}
RESUMO
Na tentativa de apresentar uma proposta de psicologia clínica diferente dos modelos de psicoterapia que se pautam nas ciências naturais, serão apresentados argumentos em defesa de uma perspectiva clínica em psicologia com base na fenomenologia hermenêutica tal como desenvolvida por Martin Heidegger. Para tanto, serão consideradas: 1- a indissociabilidade e não a dicotomia homem e mundo; 2- o caráter epocal em que a existência se dá em oposição ao caráter ahistórico da constituição do homem. 3- a técnica não mais como um meio para atingir um fim, mas como horizonte histórico de determinação das crises existenciais. Por fim, mostrará que a clínica que tem como base a existência consiste apenas em uma tentativa de pensar a psicologia como um espaço de tematização das questões trazidas pelo analisando, para quem as transformações existenciais apontam como possibilidades e não como necessidades.
\end{abstract}

Palavras-chave: Fenomenologia-hermenêutica; Heidegger; existência; psicologia clínica.

\begin{abstract}
In an attempt to present a proposal for a clinical psychology of different models of psychotherapy that are implemented in natural sciences, our intention is to bring arguments in defense of a perspective of clinical psychology based on phenomenological hermeneutics as developed by Martin Heidegger. To do so, will be: 1-the inseparability and not the dichotomy man and world; 2-the epochal character in that existence is in opposition to the not history of the constitution of man's character. 3-To think the technique no longer as a means to an end, but as a historical horizon in that existential crisis happen. Finally, it will show that the clinic which is based on the existence consists only in an attempt to think psychology as an area of thematization of the issues brought by analyzing, for whom are possible and necessary the existential transformations.

Keywords: Phenomenology hermeneutics; Heidegger; Existential; clinical psychology.
\end{abstract}




\title{
1 Introdução
}

Tentaremos, no desenrolar deste trabalho, inscrever outras possibilidades na psicologia clínica que se encontram obscurecidas pela absolutização do psiquismo tal como tomado pela psicologia com base nas ciências da natureza. Nessa psicologia, o psiquismo é considerado uma subjetividade passível de objetivação - sujeito - e descrito pelas filosofias da subjetividade, e pela psicologia aplicada em geral, como que encarnando em sua interioridade os traumas, as rupturas e os conflitos, bem como a possibilidade de superá-los com o autoconhecimento possibilitado pela psicoterapia.

Para atender às determinações das ciências naturais na elaboração de uma prática clínica, é preciso que se cumpra, no mínimo, a exigência de elaboração de uma teoria que parta da ideia de uma interioridade psíquica passível de ser apreendida em seu aspecto universal essencial. O psiquismo humano, então, deve ser passível de objetivação e da consequente definição, para que assim se encontrem seus sentidos e determinações. E para que a prática psicoterápica efetivamente se dê, precisamos dispor de meios e procedimentos que permitam a autorrevelação libertadora desse psiquismo. Este, nos termos das ciências naturais, é, na maioria das vezes, desconhecido para si mesmo. Sá e Mattar (2008) acrescentam que esse modo como a psicoterapia se constituiu foi fortemente influenciado pela perspectiva funcionalista amplamente divulgada no final do século XIX:

\begin{abstract}
Apesar da heterogeneidade e da diversidade de práticas que encontramos no cenário da Psicologia Clínica, permanece ainda hoje, embora muitas vezes de forma não tematizada, a ideia da psicoterapia como psicologia aplicada, visando à produção de efeitos determinados, dentro de certas margens de controle e previsibilidade. (SÁ; MATTAR, 2008, p. 191)
\end{abstract}

Em 1890, William James assume que pretende fazer da psicologia uma ciência natural, tal como se observa mais tarde em seu artigo intitulado "Apelo para que a psicologia seja uma ciência natural", no qual ele afirma:

O tipo de psicologia que poderia curar um caso de melancolia ou afastar uma insana desilusão crônica certamente deveria preponderar o mais seráfico vislumbrar da natureza da alma. E esse é o tipo de psicologia que pessoas pouco ou nada afeitas à suprema racionalidade - a saber, biólogos, psiquiatras e pesquisadores psíquicos - estão certamente tendendo a ocasionar, quer os auxiliemos ou não. (JAMES, 2009, p. 324) 
James, ainda defendendo o caráter pragmático da psicologia, afirma o seguinte, em Principles of Psychology: "os mecanismos psicológicos existem porque são úteis e auxiliam os indivíduos a sobreviver e realizar atividades importantes para a adaptação às exigências do meio" (JAMES apud TOURINHO, 2009, p. 30). Nesse sentido, o pragmatismo encontra-se presente uma vez que esta perspectiva avalia o psiquismo humano como constituído por um mecanismo que visa sempre a consequências práticas, logo a determinação psíquica se constitui teologicamente. Importa, então, ao investigador do fenômeno psíquico, conhecer as operações das atividades mentais ao buscar as metas futuras e a escolha dos meios para alcançá-las em circunstâncias reais. O pensar, o sentir e os motivos vão paulatinamente se modelando para atender às exigências utilitárias advindas do mundo, até se adaptarem ao meio e se tornarem autônomos. Com o conhecimento dessas funções do psiquismo por parte dos psicólogos modernos, poderiam eles prever e controlar as ações humanas e, assim, ensinar aos homens como deveriam agir de modo a resolver seus problemas. Em síntese, a constituição das teorias e práticas em psicologia, inspirada nos critérios das ciências naturais, tal como elaborada por William James, dentre outros, considera a substancialidade do psiquismo e suas determinações passíveis de serem apreendidas empiricamente. Daí caber ao estudioso da psicologia conhecer os critérios de uma normalidade psíquica para então elaborar as suas práticas com o auxílio de técnicas que possibilitem o ajustamento e a adaptação daquele cujo psiquismo se encontra desajustado.

Pretendemos aqui apresentar uma proposta de realização da clínica psicológica com a utilização de elementos que escapem das determinações das ciências naturais, tanto com relação às postulações teóricas acerca do psiquismo quanto das práticas que objetivam abrir um acesso às verdades desse psiquismo. Para construir nossa proposta, aproximar-nos-emos da fenomenologia hermenêutica a fim de, então, alcançar elementos que nos permitam pensar as bases de uma clínica psicológica que parta da ideia de Dasein tal como desenvolvida por Heidegger (1988) e já iniciada pelos psiquiatras L. Binswanger e Medard Boss.

L. Binswanger e M. Boss, nos idos de 1940, lançaram uma proposta clinica com base no pensamento de Heidegger que eles denominaram Daseinsanálise. Feijoo (2011) esclarece acerca da constituição inicial da Dasensanálise por esses dois estudiosos da seguinte forma:

Ludwig Binswanger, que vai tomar como referência as noções heideggerianas de projeto e cuidado, considera a questão da existência humana como ser-aí em seu caráter de indeterminação, finitude e poder-ser. O segundo estudioso desse tema é Medard Boss, que toma de Heidegger a temática das tonalidades afetivas da angústia e do tédio. 
Este é considerado por Medard Boss como a tonalidade afetiva que abarca o homem em um mundo onde o que predomina é o horizonte da técnica. (FEIJOO, 2011, p. 23).

Cabe, então, questionar o porquê de se propor uma clínica já anteriormente apresentada. Ocorre que pelo fato de Boss e Binswanger terem iniciado essa proposta clínica e ambos terem migrado da psicanálise, as suas daseinsanálises ainda trazem elementos de uma psicodinâmica psicanalítica. E esses elementos ainda apresentam aspectos contraditórios com a hermenêutica heideggeriana. Ressaltamos, também, que durante todo o intervalo de 1940 até os dias de hoje encontramos raríssimos trabalhos de pesquisa nessa perspectiva. Feijoo (2011) ao deter-se nesse tema, chama a atenção para o fato de que o próprio Heidegger não reconhecera em Binswanger elementos suficientemente embasados, principalmente com relação às teorizações acerca do amor, que caracterizassem uma Análise do Dasein. "Medard Boss (1954) parece que ainda guarda em sua daseinsanálise elementos elaborados por Binswanger, como, por exemplo, a importância das relações de amor para alcançar a libertação" (FEIJOO, 2011, p. 72).

Pelos motivos expostos acima é que acreditamos ser necessário continuar as investigações acerca dessa temática na clínica. Para continuar a trilhar o caminho de uma clínica com base no pensamento de Heidegger vamos, em Ser e tempo, procurar subsídios para pensar a existência prescindindo da noção de psiquismo substancializado para, assim, podermos passar a considerar a existência como se constituindo em fluxo constante, em meio ao horizonte histórico em que ela se encontra. Nos escritos de Heidegger a partir de 1929, encontramos, também, as bases para compreender as determinações presentes em nosso horizonte histórico, que nos permitem entender que as crises existenciais ocorrem quando, em uma tentativa de corresponder às solicitações do mundo, abafamos as tonalidades afetivas fundamentais que nesse mesmo horizonte emergem.

Heidegger, com as considerações acerca da desconstrução e prescindibilidade da subjetividade, subtrai do ser-aí propriedades ontológicas previamente dadas. Com isso, a existência, ao mesmo tempo em que se define por sua nadidade, logo sem nenhuma propriedade que a determine a princípio, destina-se obrigatoriamente a ter de ser para conquistar o seu ser. Ao tomar a existência em seu caráter finito, logo, em seu espaço próprio de realização da singularidade do ser-aí, e temporal, em fluxo, conquistamos elementos que nos indicam o caminho para assumir uma posição que rompa com a ideia de interioridade psíquica, bem como de uma clínica cujo fim seja a superação pelo autoconhecimento. Desse modo, poderemos abrir outro espaço possível à clínica psicológica, 
que denominamos de existencial. Mas cabe perguntar: qual e como seria esse caminho? É isso que tentaremos desenvolver a seguir. A tarefa é de tamanha dificuldade que, muito frequentemente, alguns estudiosos do assunto chegam a afirmar veemente que se trata de um empreendimento fadado ao fracasso. Teriam razão esses estudiosos? Será que eles visualizam pontos de tensão que impediriam que a psicologia clínica pudesse ser posta em outras bases que não as da ciência natural?

Por se tratar de uma tarefa árdua é que precisamos, primeiramente, poder ver a psicologia clínica sem as implicações de uma perspectiva das ciências naturais e nem mesmo do senso comum. Se assim não for, uma outra visada fica impossibilitada, uma vez que as referências de uma psicologia aplicada torna inviável outro posicionamento que transgrida suas referências.

Uma vez assumida uma atitude fenomenológica hermenêutica frente ao fenômeno que pretendemos trazer à discussão, passamos a refletir acerca das referências que tornam viável a possiblidade de uma clinica psicológica inspirada nas reflexões heideggerianas. Primeiramente, é importante que coloquemos em relevo a dissociação entre ser-aí e mundo histórico. Com a noção de ser-aí, pretendemos pensar as bases de uma clínica psicológica que parte da ideia de Dasein tal como desenvolvida por Heidegger em Ser e tempo. Isso implica que pensar a existência para além da noção de sujeito já que a ideia de sujeito apartado do mundo foi hegemônica na constituição das teorias e práticas psicológicas.

Com a noção de mundo histórico, tal como desenvolvida por Heidegger, em um segundo momento de suas obras, traremos à discussão a possibilidade de pensar as crises existenciais a partir daquilo que se apresenta no horizonte histórico em que acontecem. Isso consiste em deslocar-se da dicotomia homem e mundo e deixar de atribuir este último as mazelas da vida singular. Essa noção advém de uma inspiração romântica na constituição das teorias e práticas em psicologia. Assim, pela perspectiva do Dasein pretendemos abrir um outro horizonte de tematização da psicologia para que, com a apropriação de elementos fenomenológicoexistenciais, possamos encaminhar uma reinterpretação da clínica psicológica.

Iniciaremos nossa exposição de argumentos que viabilizam a psicologia fenomenológico-existencial mostrando como a temática desenvolvida em Ser e tempo já é uma tentativa de sair do campo da lógica pela qual a subjetividade se constitui e também do campo empírico pelo qual o sujeito é tomado como constituído de determinações do âmbito do natural. Passamos, então, a trazer à discussão as determinações com seu cunho existencial, portanto não se limitando a uma interioridade, nem a uma exterioridade, mas ao espaço que não é nem interior e nem exterior. Trata-se do espaço de 
copertencimento do dito interior e exterior, e assim retomamos a existência em sua originalidade.

\section{A retomada da existência}

Heidegger, em Ser e tempo (1988), desenvolve uma filosofia com pretensões de retomar a existência em sua faticidade, a qual havia sido suprimida pelas filosofias idealistas e empiristas em uma tentativa de resolver a dicotomia sujeito e mundo. Eis a discussão do filósofo que pode permitir à psicologia um diálogo afinado com a filosofia de modo a possibilitar outra direção nos estudos psicológicos, além daqueles que partem da noção de um eu posicionado ou de um eu objeto. O filósofo do Dasein, em sua analítica existencial, tenta esclarecer a dinâmica finita da existência do ser-aí humano. É nesse aspecto que encontramos a importância dessa analítica da existência para a psicologia, visto que é justo a existência o conceito-chave de que a psicologia clínica com bases existenciais se apropria para estabelecer outro modo do pensamento e da prática clínica.

Comecemos então a esclarecer a dinâmica do ser-aí como articulada por Heidegger para então depois reposicionarmos a psicologia clínica. Para esse filósofo (1988), no ser-ai sua essência é existência, enquanto existir significa ek-sistir, ser-arremessado-para-fora-de-si, jogado em direção ao horizonte histórico-mundano de realização de si. Defrontamo-nos então com um problema: como pensar uma clínica sem um objeto determinado a ser lapidado? Para discutirmos o problema em questão, começaremos a apresentar como Heidegger desenvolve a noção de ser-aí. Para tanto, faz-se necessário que ressaltemos três outras temáticas: mundo, era da técnica e tonalidades afetivas fundamentais que também estão em jogo quando se pretende defender uma psicologia clínica fundamentada na fenomenologia e na hermenêutica tal como desenvolvidas por Heidegger em suas obras.

\subsection{Ser-aí (Dasein)}

Heidegger (1988), para deixar evidente o caráter da existência como espaço de constituição do ser-aí, esclarece dois aspectos pelos quais tudo se inicia: a indeterminação e a negatividade do ser-aí. Com isso, ele mostra que a existência não pode ser tomada como um substrato material que possui determinações e faculdades, passando a referirse ao Dasein como apenas modos de ser do homem (ser-aí). E como tal, trata-se de um ser sempre articulado a sua historicidade - aí. O filósofo esclarece que o ser-aí é um ente privilegiado por ser capaz de interrogar o ser, e que somente pelo exame fenomenológico desse existente se poderá chegar à noção do sentido do ser em geral. 
Heidegger inicia pela apresentação das características constitutivas do ser-aí: 1) primado da existência frente à essência, que indica que sua essência consiste em sua existência; 2) ser sempre meu, que aponta para o caráter de singularidade do ser-aí, por isso a impossibilidade de compreendê-lo fora de suas expressões singulares; 3) o ser-aí é marcado pela lógica do ter de ser, fundamento da responsabilidade com o seu existir; 4) caráter do poder ser, o que caracteriza a incompletude ontológica do ser-aí. Considerando o ser-aí em sua incompletude, indeterminação ontológica e ao mesmo tempo tendo o compromisso de ter de ser em sua expressão singular, como afinal chega o existente a ser o que é? É justamente nesse ponto que entra em jogo o seu aí, caráter histórico-fático de sua existência, sem o qual o ser-aí jamais se constituiria, visto que, de início, ele não é nada. Daí tornar-se imprescindível a tematização do horizonte histórico em que a existência se constitui.

\subsection{Mundo: horizonte histórico}

Mundo histórico diz respeito ao sentido da existência como acontecimento histórico. Já que a existência se apresenta no início em sua indeterminação originária e consequente poder ser, é o mundo com suas possibilidades, também originárias, que se apresenta com orientações do que, como e para que afinal se existe. Logo, a existência se constitui em uma relação de copertença ser e aí. Mas é exatamente esse modo de constituição do ser-aí que, ao mesmo tempo em que é liberdade, é também aprisionamento. É liberdade pelo seu caráter de poder ser e é aprisionamento por se constituir por meio das orientações próprias do seu horizonte histórico - aí -, em que o ser-aí se encontra e se expressa.

Heidegger (1958) observa que cada período histórico apresenta certo modo de orientações. Ele argumenta que estamos na "Era da técnica", logo é nas determinações do mundo da técnica que nos constituímos no início e na maioria das vezes. Mas quais são essas determinações que constituem e ao mesmo tempo aprisionam o seraí a um determinado modo de ser? Uma caracterização que fundamenta todas as outras é a constante e incessante luta contra a negatividade da existência. Daí constituir-se na era da técnica uma metafísica da presença constante do ser, operando-se, desse modo, uma total retração do caráter de negatividade da existência. A tarefa da metafísica passa a ser a busca das certezas, das definições e das constâncias. Logo, ao eliminar a historicidade do espaço de constituição da existência, obscurece-se o caráter de historicidade em que ela sempre se constitui. Portanto, introduzindo o caráter de historicidade à constituição do ser-aí, cabe questionar: quais seriam as determinações de nosso horizonte histórico em que nos 
constituímos e permanecemos aprisionados? O que fazer para não permanecermos aprisionados às proposições de nossa era?

\section{3 "Era da técnica"}

Primeiramente, temos de trazer para discussão questões que aparecem na era da técnica para prestar esclarecimentos do nosso horizonte. Heidegger (1958) recomenda não assumirmos frente à técnica uma atitude neutra, de negação ou de afirmação, mas, antes de tudo, que questionemos, pois questionando constrói-se um caminho em que a exigência é atentar-se ao caminho. Apenas questionando algo é que podemos nos preparar para uma relação livre com aquilo que nos pode aprisionar. Heidegger (1958) então interroga sobre o que é a técnica em sua verdade não técnica: qual a sua essência? Ele mesmo responde que a essência da técnica só pode ser revelada quando a noção de instrumentalidade (meio para atingir um fim), tal como tomada na concepção corrente da técnica, for esclarecida.

E, assim, afirma Heidegger (1958) sobre as determinações instrumental e antropológica da técnica, que, uma vez tomadas por verdadeiras e exatas, não podem ser questionadas. Voltemo-nos, então, a questionar aquilo que a princípio prescinde de questionamento. A essência da técnica tal como compreendida em uma determinação antropológica é a causalidade. Mas qual é a essência da causalidade? Responde o filósofo alemão que a essência da causalidade é um ocasionar, tal como formulada por Aristóteles sobre as quatro causas solidárias entre si, como modos do ato pelo qual se responde. Ocasionar é deixar vir à presença o que ainda não se apresenta, ou seja, o que a partir de si se apresenta é um produzir. A técnica então não é um meio para chegar a um fim; em sua essência encontramos um modo de desabrigar, é um desvelar. A técnica moderna, então, é um modo possível de desvelamento da realidade. Interessa-nos, então, saber de que modo esse desabrigar da realidade aparece como determinações do modo de ser em nosso horizonte histórico.

O modo de desabrigar do real, no horizonte da técnica moderna, ocorre considerando apenas uma das quatro causas aristotélicas, trata-se de um total encurtamento a uma só causa: a eficiente. Esta totalmente articulada à produção de um efeito. Passa a ser verdade aquilo que funciona e que tem como provar seus efeitos, resultados. Importam os resultados conquistados com a produção, mas trata-se da produção que desabriga o real como depósito de reservas. 0 desvelamento que aparece na técnica moderna é a produção pela provocação da natureza, em que esta se torna matéria que deve estar à disposição com fins à acumulação. Mas, com esses esclarecimentos, ainda não alcançamos aquilo que Heidegger afirma 
ser o maior perigo das determinações da era da técnica. $\mathrm{E}$ qual seria o maior dos perigos? Ele acontece quando, aprisionados pelo primado da produção que não cessa e que aquiesce aos limites, nos esquecemos do ser e do que afinal estamos produzindo. E nessa conjuntura, Gestell, há um total obscurecimento da morada do ser, ou seja, sua historicidade. O homem esquecido de seu elemento original corre 0 perigo de retrair o verdadeiro. Mas onde há esquecimento, há também a possibilidade da lembrança capaz de corresponder aos apelos daquilo que the é mais original, Ereignis. É o acontecimento apropriativo que evoca o comum pertencimento do homem e ser que acontecem e se apropriam mutuamente. Por isso é que Heidegger (1958) afirma que questionar aquilo em que estamos imersos é preparar-se para uma relação mais livre com aquilo que se apresenta. Abre-se, assim um espaço de alteridade em relação à técnica. Cabe agora perguntar: mas como estabelecer essa relação livre, como questionar nossas determinações se estamos imersos nelas?

É preciso que aconteça uma transformação, ainda que esta não possa jamais ser produzida. A verdadeira transformação acontece em um espaço que se abre como espaço de alteridade, em que precisamos apenas nos deixar tocar por ele para que a possibilidade de transformação possa acontecer. E, para que esse espaço de abertura às transformações possa se abrir, é preciso que as crises aconteçam. Vamos então pensar para que assim possamos trazer à lembrança as crises existenciais do ser-aí no horizonte histórico em que nos encontramos, mas que se encontram obscurecidas, retraídas e assim não se apresentam como possibilidade. As crises existenciais a que nos vamos reportar em nossa discussão aparecem graças a tonalidades afetivas fundamentais.

\subsection{As tonalidades afetivas fundamentais e o descortinar de possibilidades}

Para Heidegger (2006), são as tonalidades afetivas fundamentais que se constituem em uma atmosfera que promove a possibilidade de uma saída da restrição e do estreitamento das possibilidades existenciais. Acontece que, na maioria das vezes, tendemos a encobrir tais tonalidades. A tentativa de encobrimento da verdade do ser, ou seja, seu caráter de indeterminação, finitude e vulnerabilidade, acaba acontecendo pela restrição de sentidos. Heidegger (1958) pensa o cotidiano em uma perspectiva do comportamento mediano na era da técnica, com o qual temos a impressão de que somos determinados, temos o controle e que podemos viver imersos na novidade. Agimos de modo a acreditar que a nossa vida nos pertence e que nada pode ameaçar nossa existência. E toda vez que temos o anúncio do incontrolável e do 
indeterminado tendemos, no início e na maioria das vezes, a retornar à tutela do impessoal. Acontece que quando as tonalidades afetivas fundamentais surgem e rompem com as determinações sedimentadas, outras possibilidades são descortinadas. E assim abrese a possibilidade de uma saída singular.

Para avançarmos um pouco mais, precisamos ainda questionar sobre, afinal, o que seria uma psicologia e, consequentemente, uma clínica psicológica que mantivesse a ideia de existência tal como primeiramente desenvolvida por Kierkegaard, ou seja, totalmente indeterminada. É com Heidegger - já que este pretende se afastar das filosofias que ele mesmo denominou filosofias da subjetividade, desconstruindo a ideia de sujeito e pensando a existência como negatividade, logo prescindindo de todo e qualquer psiquismo - que vamos dialogar.

\section{A clínica psicológica de inspiração fenomenológico- existencial}

Ao retiramos a situação problema da esfera da interioridade e a colocarmos no espaço de acontecimento da existência -aí - aparece o fato de estarmos lançados e de que as coisas não se realizam por uma questão apenas de força e determinação pessoais. Há situações que são próprias ao nosso horizonte epocal, e nele estamos lançados. E como atuará então o profissional psi que assim pensa a existência? Ele, o psicólogo, parafraseando Kierkegaard (1987), desfaz os laços da ilusão, para que assim o iludido possa desvelar a sua situação e nela assumir outras possibilidades que parecem obscurecidas pela restrição da sua existência a um só possível. Por isso o psicólogo clínico jamais assume o lugar do especialista que conhece as verdades do psiquismo bem como desconhece o caminho de acesso a suas verdades.

Na clínica existencial, o psicólogo analista apenas participa, mas não comanda, nem determina, nem posiciona. No entanto, a sua participação é decisiva para que aconteça um jogo em que o analista e o analisando abram um espaço de abertura para possibilidades que se encontram obscurecidas, para que essas possam transparecer. Para tanto, esse analista precisa ao menos, como diz Kierkegaard (1987), da adição. Isso quer dizer que já tenha questionado as imposições, orientações sedimentadas ou retóricas hegemônicas presentes em nosso horizonte histórico. Só assim o psicólogo clínico poderá no mínimo não sedimentar ainda mais a retórica, que, no final das contas, nos mantém totalmente aprisionados às determinações hegemônicas desse horizonte. Novaes e Mattar corroboram essa posição ao afirmarem: 


\begin{abstract}
Uma vez que as demandas do sofrimento existencial, endereçadas à clínica psicoterápica, cada vez mais estão relacionadas ao nivelamento histórico de sentido que pode ser computado no cálculo global de exploração e consumo, é imprescindível, para que a psicoterapia possa se constituir em um espaço de reflexão propiciador de outros modos de existir, que ela própria não permaneça subordinada a esse mesmo horizonte histórico de redução de sentido. (NOVAES e MATTAR, 2008, p.191)
\end{abstract}

Mas cabe então uma pergunta: como efetivamente o psicólogo clínico vai atuar para que possam surgir outros modos de existir? O clínico acompanha aquele que sofre naquilo que ele tem a dizer e a lamentar, aguarda pacientemente que, frente à dor, outras possibilidades apareçam. E assim, no momento em que, com coragem, aquele que está em sofrimento vislumbra outras possibilidades, o clínico continua a acompanhá-lo de modo a aguardar que a transformação possa acontecer. Como esclarece Cabral (2012, no prelo):

Isso significa dizer que o terapeuta e a terapia são elementos de um jogo que abre as portas para a simples possibilidade do acontecimento da reinvenção de si. Enquanto salvaguardador dessa simples possibilidade, o terapeuta atinge sua riqueza, mesmo que se mova na precariedade assinalada pela falta de modelos teóricos que expliquem o ser humano. Tarefa que exige um novo aprendizado para conquistar a sabedoria da docta ignorantia daqueles que, ao lado do outro, participam favoravelmente de sua travessia existencial, sem lançar mão de ideias universais de homem e de suas aplicações corretivo-morais na existência alheia. Essa perspectiva na clínica tem sua "positividade", não aniquila por meio de seus exercícios de destruição da tradição a possibilidade da clínica, mas lança-lhe novos horizontes. (CABRAL, 2012, no prelo.)

Considerando que são as tonalidades afetivas fundamentais que, ao abrir um espaço para que as crises se instaurem, têm o poder de suspender as prescrições do mundo fático em que nos encontramos e assim permitir que outras possibilidades apareçam como tais, abrindo espaço para uma libertação das condições hegemônicas de uma determinada atmosfera, como fazer para deixar que tal atmosfera aconteça?

$\mathrm{Na}$ tentativa de responder a essas questões, vamos atentar para o que diz Cabral (2012, no prelo) ao referir-se à necessidade de empreender uma "redução fenomenológica, entendida como recondução do conhecimento ao topos, onde um fenômeno vem a ser o que ele é" (HUSSERL apud CABRAL, 2012, no prelo.). Uma vez alcançado o sentido primeiro, sentido este que unifica e articula todos os elementos, podemos pensar a unidade da pluralidade conjectural 
dos elementos. E esse sentido, por ser fenomenologicamente constituído, e, portanto não se tratar de algo determinado empiricamente, abre a possibilidade de experiências outras, que também se encontram hermeneuticamente determinadas.

Qual é o topos e o sentido da experiência daqueles que buscam a clínica pela dor de seu projeto de vida conjugal frustrado? O que dizer àqueles que se referem à solidão, ao abandono, à exclusão? E com relação ao temor do fracasso, onde encontramos a gênese dessa questão? Do que as pessoas estão falando ao se referirem ao eterno cansaço? É na busca da situação mais originária, que está encoberta pelas determinações hegemônicas no horizonte histórico de sentido em que nos encontramos, que podemos desocultar outras possibilidades. E é nesse horizonte que se abre a possibilidade de que a clínica psicológica encontre outro espaço de realização, o qual se estrutura no pressuposto de que o ente que somos é um poder ser afetivamente articulado com o mundo histórico do qual faz parte, e incessantemente tem que dar conta de sua finitude constitutiva, e, ainda, na situação de que aquilo que somos e como nos constituímos se conquista performaticamente.

\section{Considerações finais}

A psicoterapia como comumente é conhecida é uma técnica, que possui instrumentos e ferramentas sustentados em um arcabouço teórico que permite ao psicoterapeuta desvendar os segredos e verdades que se encontram no interior de uma subjetividade. Assim, aquele que não conhece a verdade de si pode, uma vez conquistando-a, superar os seus conflitos e ganhar liberdade e autodomínio.

Um outro caminho a trilhar consiste em assumir o método fenomenológico hermenêutico na clínica psicológica, que pretende deixar que no próprio caminhar o caminho apareça. Por isso é que cada horizonte histórico traz as tensões que lhe são próprias. E essas tensões só podem aparecer nas expressões singulares.

Parece que, aos estudiosos do assunto que afirmam a inviabilidade de se pensar uma clínica psicológica em termos existenciais, os argumentos defendidos revelam o contrário. A psicologia e sua prática clínica podem ser postas em outras bases que não as da ciência natural. E isso acontece quando abandonamos a ideia de uma subjetividade lógica ou empírica e pensamos o modo como o homem se expressa em termos do ser-aí, da existência. Deixamos de pensar o mundo em dicotomia com o sujeito e passamos a consideram a cooriginalidade homem e mundo. As crises existenciais não mais serão tomadas como algo do âmbito de uma interioridade, mas sim como determinações que se constituem em um dado horizonte histórico em 
que universal e singular se entrelaçam. Saúde psíquica não é mais algo que acontece quando um psiquismo conquista autonomia e liberdade ao descobrir a verdade de si. São as tonalidades afetivas fundamentais que, ao suspenderem as prescrições hegemônicas em um determinado horizonte histórico, deixam transparecer outras possibilidades que se encontravam obscurecidas.

Vimos, que ao trazer à discussão o caráter de abertura e histórico em que a existência se constitui, conquistamos a possibilidade de uma reinterpretação da clínica psicológica existencial. Primeiramente, ao deslocarmo-nos da ideia de que os problemas existenciais dizem respeito a uma fissura na interioridade psíquica, pensamos que as crises são existenciais porque dizem respeito ao ethos, espaço compartilhado, em que nos encontramos e que tem em sua base um horizonte historicamente constituído. Assim passamos a inscrever novas possibilidades na psicologia que se encontravam obscurecidas pelo pensamento dominante. Essa apropriação de um outro espaço clínico, que vem marcado por sua negatividade porque não dispõe de fundamentos teóricos e práticos, consiste em acompanhar a possibilidade de que as transformações existenciais ou metamorfoses possam acontecer e não que necessariamente aconteçam.

\section{Referências}

CABRAL, A. Da crise do sujeito à superação da confissão clínica: sobre a obra $A$ existência para além do sujeito, de Ana Maria Lopez Calvo de Feijoo. Estudos e Pesquisas em Psicologia, Rio de Janeiro, v. 12, n. 3, 2012. (No prelo)

FEIJOO, A. M. A existência para além do sujeito: a crise da subjetividade moderna e suas repercussões para a possibilidade de uma clínica psicológica com fundamentos fenomenológicoexistenciais. Rio de Janeiro: Viaverita Editora, 2011.

KIERKEGAARD, S. Mi punto de vista. Madrid: Aguilar, 1987.

HEIDEGGER, M. Ser e tempo. (M. Cavalcanti, Trad.). Petrópolis, RJ: Vozes. Parte I, II., 1988.

La question de la technique. In:

. Essais et

conférences. Paris: Gallimard, 1958. p. 9-49.

Seminários de Zollikon. (Arnhold, G., \& Prado, M. F., Trad.). Petrópolis: Vozes, 2001.

Os conceitos fundamentais da metafísica: mundo, finitude e solidão Rio de Janeiro: Forense Universitária, 2006.

JAMES, W. Apelo para que a psicologia seja uma "ciência natural". Scientiae Studia, São Paulo, v. 7, n. 2, p. 317-324, 2009.

SÁ, R. N.; MATTAR, C. M. Os sentidos da "análise" e "analítica" no pensamento de Heidegger e suas implicações para a psicoterapia. 
Estudos e Pesquisas em Psicologia, Rio de Janeiro, v. 8, n. 2, p. 191-203, 2008.

TOURINHO. C. Fundamentos epistemológicos da Psicologia. In: (Org.). Estudos em psicologia: uma introdução. Rio de Janeiro: Proclama Editora, 2009.

\section{Endereço para correspondência}

\section{Ana Maria Lopez Calvo de Feijoo}

Rua Barão de Piracinunga, 62 - Tijuca - Rio de Janeiro, RJ, Brasil.

Endereço eletrônico: ana.maria.feijoo@gmail.com

Recebido em: 12/06/2012

Reformulado em: 26/07/2012

Aceito para publicação em: 11/11/2012

Acompanhamento do processo editorial: Ana Maria Jacó Vilela

\section{Notas}

*Doutora em psicologia pela UFRJ, Professor Adjunto do Departamento de Psicologia Clínica e do Programa de Pós- Graduação em Psicologia Social do Estado do Rio de Janeiro 